\title{
Avaliação das aprendizagens - conceções e práticas seguidas por professores de
}

\author{
matemática
}

\section{Learning evaluation - conceptions and practices followed by mathematics}

\author{
teachers
}

\author{
Adelaide Fahe*, Manuel Vara Pires** \\ *Universidade de São Tomé e Príncipe, **Escola Superior de Educação do Instituto Politécnico de Bragança, Portugal
}

\begin{abstract}
Resumo
Este trabalho pretende identificar e analisar conceções e práticas de avaliação das aprendizagens de dois professores de matemática santomenses do ensino superior, destacando fatores que condicionam essas conceções e práticas. $\mathrm{O}$ estudo segue uma abordagem metodológica de natureza qualitativa através de dois estudos de casos. A triangulação dos dados, recolhidos através de questionários, entrevistas e análise de instrumentos de avaliação, revela que os professores refletem, nos seus discursos, conceções associadas a uma avaliação para a aprendizagem, enquanto as suas práticas estão mais próximas de uma avaliação da aprendizagem, reforçando a sua função classificativa.

Palavras-chave: avaliação para a aprendizagem, conceções, ensino superior, práticas de avaliação, professor de matemática.
\end{abstract}

\begin{abstract}
This work seeks to identify and analyze conceptions and learning evaluation practices of two STP mathematics teachers in higher education, highlighting some factors that influence these conceptions and practices. The study follows a qualitative methodological approach using two case studies. The triangulation of data, collected through questionnaires, interviews and analysis of evaluation materials, reveals that teachers reflect, in their speeches, conceptions associated with evaluation for learning, as their practices are closer to an evaluation of learning, reinforcing its classification function.

Keywords: evaluation for learning, conceptions, higher education, evaluation practices, mathematics teacher.
\end{abstract}

\section{Introdução}

Os discursos e os debates sobre a avaliação das aprendizagens no ensino superior em São Tomé e Príncipe ainda não constituem um fenómeno de atualidade educativa, contrariamente ao que se vive nos ensinos básico e secundário do país e em todos os níveis de ensino em outros cantos do mundo. O trabalho, que ora se apresenta, faz parte de um estudo pioneiro sobre a temática, realizado no âmbito de uma dissertação do mestrado em ensino das ciências. Almejando contribuir para a reflexão sobre as práticas de avaliação desenvolvidas no ensino superior, este estudo decorre da convicção de que as mudanças nas práticas pedagógicas ocorrem sustentadas na reflexão crítica dos professores sobre as mesmas e sobre os contextos em que interagem, conduzindo-os a um melhor entendimento das suas ações e das teorias que lhes são implícitas (Hoffmann, 2008). A avaliação é considerada uma área de investigação complicada, pois as conceções declaradas são muitas das vezes ilusórias. Mas o estudo das mesmas é inequivocamente fundamental, pois ajuda a compreender e entender o porquê das coisas, conduzindo em muitos casos a uma mudança desejável de atitudes (Fernandes, 2004; Hoffmann, 2008; Luckesi, 1999; Perrenoud, 1999).

Neste âmbito realizou-se um estudo com dois professores de matemática do Instituto Superior Politécnico de São Tomé e Príncipe (ISP-STP) no sentido de identificar e analisar as suas conceções e práticas de avaliação das aprendizagens dos alunos. Deste modo, foi proporcionado um contexto e uma oportunidade para os professores refletirem sobre o que pensam e o que fazem, confrontando as duas dimensões. Para isso, elegeram-se questões norteadoras da investigação em três dimensões principais: (i) Que conceções revelam os professores de matemática sobre a avaliação? Quais as perceções que estes professores apresentam sobre as formas de avaliar a aprendizagem de seus alunos na disciplina de matemática?; (ii) Que práticas de avaliação esses professores seguem na sala de aulas? Que estratégias, técnicas e instrumentos de avaliação usam?; e (iii) Que fatores condicionam as suas práticas avaliativas? Que fatores incidem positiva ou negativamente na ação ao elaborar, organizar e desenvolver a sua atividade avaliativa?

Mas o que é avaliar? Na próxima secção discute-se o conceito de avaliação e a evolução na aborgadem ao estudo de conceções e práticas avaliativas. Depois, sucessivamente, referem-se aspetos metodológicos da investigação adotada, apresentam-se dados recolhidos e realçam-se as conclusões mais significativas.

\section{Perspetivas em avaliação das aprendizagens}

O termo "avaliar" tem a sua origem no latim, derivado da composição "a+valere", que significa "dar valor a" ou "atribuir valor e mérito ao objeto em estudo" (Luckesi, 1995, p.7). Tradicionalmente, a avaliação, entendida como "medida das capacidades e do produto" (Chaves, 2003, p.11), era concretizada por meios de provas cujas perguntas valorizavam a capacidade de memorização e 
visava, essencialmente, medir para classificar e selecionar - aprovado ou reprovado. A herança desses tempos serve até hoje como catalisadora de práticas de uma avaliação seletiva que aponta o fracasso e a inaptidão sem, no entanto, apresentar perspetivas para reverter a situação, inviabilizando assim que o "errado" sirva de referências para acertos futuros (Abrantes, 1995; Fernandes, 2004, 2005, 2006; Hadji, 2001; Hoffmann, 2008; Luckesi, 1999; Perrenoud,1999).

Várias são as reflexões em busca de novas alternativas para uma avaliação que sirva efetivamente o ensino e a aprendizagem, pois só através de ruturas com as práticas de avaliação tradicionais poder-se-á alcançar mudanças significativas e desejadas no processo de avaliação para a aprendizagem. Guba e Lincoln, citados por Chaves (2003) e Fernandes (2004), afirmam que, nas últimas décadas, a avaliação atravessou, pelo menos, quatro gerações: geração de medida, geração descritiva, geração de julgamento e geração de negociação. Nas três primeiras gerações, a avaliação era vista como predominantemente classificatória e na quarta, mais recente, a avaliação é conceituada como um processo refletivo, construído, interativo e negociado, fundamentando-se num paradigma construtivista. De um paradigma de "fragmentação mecânica" tem-se evoluído para um paradigma dito multidimensional no processo de construção e reconstrução do conhecimento, em que a interdependência das relações entre o sujeito e o seu contexto propicia formas diferentes de pensar, de fazer e de agir.

A tendência é, então, considerar a avaliação como uma prática integrada no processo de ensino e aprendizagem, assumindo uma natureza orientadora e reguladora, tanto para o professor como para o aluno, favorecendo a promoção das aprendizagens (Fernandes, 2004, 2005, 2006; Luckesi, 1999; Perrenoud, 1999; Sant'Anna, 1995). A avaliação é entendida como um instrumento privilegiado de uma regulação contínua das intervenções e das situações didáticas. O seu papel não deve ser mais unicamente classificar, mas antes orientar o professor quanto à progressão dos alunos. Nesta perspetiva, a conceção de avaliação deixa de ser vista como medida ou como produto verificável de forma descontextualizada, assumindo-se mais como um processo contínuo e cumulativo capaz de contribuir para a aprendizagem e o desenvolvimento dos alunos. Hoffmann (2008) defende que avaliar é incentivar oportunidades de ação-reflexão nos alunos, através de um acompanhamento permanente do professor. Pela sua função, o professor deve proporcionar-lhes reflexões acerca do mundo, como seres críticos e participativos na construção do seu próprio saber, realçando a natureza formativa $\mathrm{e}$ mediadora da avaliação.

Este novo paradigma, opondo-se ao modelo de "transmitir-verificar-registar", está assente numa avaliação reflexiva, desafiadora e pedagógica, que promova e sirva a aprendizagem. Mas, como refere Hadji (2001), a transição de uma avaliação normativa para formativa implica necessariamente uma mudança das práticas dos professores, que devem compreender que o aluno é o ponto de partida e de chegada do processo de aprendizagem. $\mathrm{O}$ seu progresso só pode ser percebido se “comparado a ele mesmo: Como estava? Como está? Como deveria estar? O que não funcionou?" (p.37), sendo esta informação sobre o progresso que a avaliação deve recolher e que é necessária. Por isso, os professores devem buscar meios e estratégias que possam auxiliar os alunos a superar as dificuldades e para se aperceberem das lacunas, tentando ultrapassá-las com a ajuda do professor e do seu próprio esforço (Hoffmann, 2008). No fundo, é esta a principal intenção formativa da avaliação (Perrenoud, 1999).

A avaliação envolve "a recolha sistemática de informação sobre a qual se possa formular um juízo de valor que facilite a tomada de decisões" (Fernandes, 2006, p.37, com itálicos da nossa responsabilidade). Na nossa ótica, esta afirmação resume bem o novo paradigma de avaliação das aprendizagens. Com a recolha recomenda-se reforçar os momentos avaliativos e as técnicas de avaliação que os professores usam, devendo a recolha ser sistemática e as técnicas serem diversificadas, de diversas fontes e em função da sua finalidade. As informações a recolher devem estar em consonância com o sujeito (aluno ou professor), com o objeto (conteúdos, temas) sobre qual recai a avaliação e com o contexto. Com o juízo de valores pretende-se destacar as apreciações feitas pelos professores sobre as informações recolhidas, feitas de forma profunda e exaustiva e usando critérios objetivos e interpessoais. Uma das questões mais polémicas na avaliação prende-se com as decisões que são tomadas uma vez feita a recolha de informações sobre a aprendizagem do aluno. Essas decisões devem ser tomadas tendo em conta as razões pela qual foi feita a "recolha de informação", pois o respetivo tratamento deve estar adequado ao objetivo pelo qual o aluno foi avaliado. A polémica surge pelo facto de, quase sempre, o propósito ser pura e simplesmente classificar pois, como salienta Arantes (2004), "em avaliação, um professor não tem a liberdade de fazer o que quer. Pode avaliar a sua ação, compreendê-la, interpretá-la e melhorá-la. Porém, o sistema obriga-o a avaliar e a divulgar o desempenho dos seus alunos, o que o encaminha para uma determinada prática" (p.16). Mas é, fundamentalmente, nos propósitos que se acentuam as diferenças entre a avaliação tradicional e o novo paradigma de avaliação. No novo paradigma, a avaliação assume várias funções, em que uma delas é de servir de "bússola" para as orientações do trabalho do professor. Como recorda Fernandes (2005), as notas e classificações atribuídas aos alunos são, em grande parte, consequências das orientações decididas pelo professor.

Nesta ótica, Hoffmann (2008) considera que é importante distinguir dois grandes tipos de avaliação: avaliação para a aprendizagem e avaliação da aprendizagem. A avaliação para a aprendizagem valoriza, basicamente, a vertente formativa, colocando a ênfase no processo de aprendizagem. Através de instrumentos de avaliação diversificados, as informações são utilizadas pelos professores para identificar as dificuldades dos alunos com vista a ultrapassá-las e contribuir para uma melhoria. $\mathrm{Na}$ avaliação da aprendizagem a ênfase é colocada no produto, isto é, nos resultados de testes escrito, tendo um caráter 
essencialmente sumativo e aceitando que o objetivo principal é classificar e seriar os alunos.

A abordagem da avaliação das aprendizagens em matemática, naturalmente, segue este debate mais amplo. Segundo Arantes (2004), a avaliação deve ser pensada, elaborada e praticada para servir a aprendizagem, transformando-se numa prática que a subsidie, informando e orientando professores e alunos na construção do conhecimento matemático. Também o National Council of Teachers of Mathematics [NCTM] (2007) defende esta perspetiva, considerando que a avaliação em matemática deve abranger diferentes dimensões, designadamente, o poder matemático, a resolução de problemas, a comunicação, o raciocínio, os conceitos matemáticos, os procedimentos matemáticos e a predisposição para a matemática.

\section{Aspetos metodológicos e contexto do estudo}

Esta pesquisa foi realizada seguindo a tradição qualitativa (Bogdan \& Biklen, 1994), respeitando as suas características descritiva e indutiva, e teve como parâmetro a vivência e a experiência de dois professores de matemática do ensino superior, a quem demos os nomes de João e Paulo. A seleção dos participantes baseou-se nos seguintes critérios: (i) ser professor do ISP, lecionando "Matemática" em diferentes cursos; (ii) abranger diferentes perfis de professor relativamente a formação, anos de serviço na docência, idade e vínculo com a instituição; e (iii) ter a disponibilidade e o consentimento do professor. As técnicas e instrumentos de recolha de dados utilizados são os propostos por Lessard-Hébert, Goyette e Boutin (2005), nomeadamente, o questionário com perguntas abertas, as entrevistas semiestruturadas e a análise documental. Para o tratamento dos dados, procedeu-se a uma análise temática descritiva selecionando citações a partir dos dados recolhidos, para ilustrar e substanciar a apresentação.

O presente estudo desenvolveu-se em três momentos consecutivos, todos de natureza descritiva e de análise qualitativa dos dados. Num primeiro momento e, através do questionário, recolheu-se informação para caracterizar os professores participantes, para compreender as suas visões sobre a disciplina de matemática e registar aspetos das suas experiências de avaliação enquanto aluno e enquanto professor. Com a primeira entrevista realizada num segundo momento do estudo, recolheu-se informação sobre conceções e práticas de avaliação desses professores. Finalmente, num terceiro momento, fez-se a análise qualitativa dos instrumentos de avaliação (teste escrito) utilizados pelos professores, seguida de uma segunda entrevista para a consolidação da informação.

A pesquisa foi desenvolvida no Instituto Superior Politécnico de São Tomé Príncipe (ISP-STP), o maior estabelecimento do ensino superior do país, no período de janeiro a abril de 2012. O ISP-STP contava com 924 alunos matriculados e distribuídos em 40 turmas em regime triplo: laboral (manhã ou tarde) e pós laboral. O corpo docente era constituído por 108 professores e 9 deles lecionavam disciplinas relacionadas com
"Matemática". O sistema de ensino do ISP-STP é democratizado, tendo cada professor autonomia para definir o programa curricular, a ser validado pelo coordenador de departamento.

O novo sistema de avaliação dos alunos (ISP-STP, 2009) estabeleceu nos seus princípios a primazia da avaliação formativa e estabeleceu três modalidades de avaliação "decorrentes da natureza de cada disciplina": a avaliação contínua, a avaliação periódica e o exame final. Para o cálculo da média final em cada disciplina, a avaliação sumativa tem o coeficiente de ponderação "três" e a avaliação contínua o coeficiente "um". Desta forma, há um choque com a "primazia da avaliação formativa", permitindo que os resultados das provas periódicas, geralmente de caráter classificatório, sejam sobrevalorizados em detrimento das observações diárias dos professores (avaliação contínua), de caráter diagnóstico e formativo.

\section{Apresentação e análise dos resultados obtidos}

A análise das respostas dos professores João e Paulo, assim como de aspetos relacionados com as suas práticas, são apresentadas a partir das três dimensões principais das questões norteadoras da pesquisa.

Que conceções revelam os professores de matemática sobre a avaliação? Quais as suas perceções sobre as formas de avaliar a aprendizagem de seus alunos na disciplina de matemática?

João associa o significado de avaliação ao conceito de avaliação formativa e reguladora. Para o professor, avaliar "consiste em ver a turma no seu todo e cada um em particular, como estão a progredir em relação aos objetivos" e considera que o papel mais importante da avaliação é "informar os professores sobre as necessidades de mudar ou não de metodologia e informar sobre como está a evoluir a aprendizagem dos alunos". Valorizando a reflexão sobre a prática e a função pedagógica da avaliação, João situa-se numa filosofia de conceção de avaliação para aprendizagem.

Quando questionado sobre o facto de classificação poder ser sinónimo de avaliação, João é perentório na sua resposta: "Não é, e nunca será" e distingue, claramente, esses dois conceitos, "avaliação é ver a evolução do aluno, enquanto [que] classificar significa, perante determinados conceitos, verificar se os alunos realizaram as tarefas de acordo com os pré-requisitos estabelecidos". Aliás, já tinha deixa bem claro no seu conceito de avaliação que avaliar vai para além de classificar.

Já Paulo revela uma conceção de avaliação mais ambígua que, pode ser associada tanto à avaliação da aprendizagem como à avaliação para a aprendizagem, estando convicto que a avaliação serve não só para orientar o professor, mas também para medir e classificar: "Eu vou avaliando num processo e que vai dar-me um resultado. Esse resultado tem duplo objetivo. Pode (...) não só pode, mas deve servir para verificar, como já tinha dito, o cumprimento dos objetivos, permitindo corrigir o método, como também apurar aqueles alunos que estão aptos a passarem para o nível superior... passar de classe ou obter diplomas". 
Quanto ao papel da avaliação, Paulo considera que os aspetos mais importantes prendem-se com a regulação do processo de ensino e aprendizagem e com a obtenção do feedback sobre a aprendizagem dos alunos. Tal como João, Paulo também considera que avaliação e classificação são atos distintos, embora a diferenciação entre os dois conceitos tenha sido mais cautelosa: "Não. Avaliar (...) é fazer como se fosse (...) não tem só a ver com o ato sumativo [classificatório] (...). Portanto, eu tenho um objetivo traçado e pretendo saber se atingi os objetivos ou não. Avaliação é um pouco disso. Classificar (...) eu no ato de avaliar posso classificar ou não (...) avaliar é pouco mais que classificar. Explorando este aspeto classificativo da avaliação, Hadji (2001) reconhece que os professores não são absolutamente livres nas opções que tomam, pois têm a obrigação, perante o sistema, de classificar para selecionar os seus alunos. Todavia, faz questão de sublinhar que os professores devem ter em mente que a avaliação tem várias funções e que classificar e selecionar podem ser as últimas etapas deste processo. As outras funções de avaliação servem justamente para preparar os alunos a serem bem classificados.

A dissemelhança entre as conceções de avaliação das aprendizagens dos dois professores é evidenciada através das imagens que cada um associa à palavra avaliação. João associa a avaliação a "sucesso", enquanto Paulo faz a associação a "raposa", um animal tradicionalmente conhecido por ser astucioso. Talvez estas associações estejam relacionadas com o percurso estudantil de cada um deles. João não sentiu grandes dificuldades na aprendizagem da matemática, encarando a avaliação como um momento para competir com os seus colegas. Já Paulo conheceu, quando estudante, algumas dificuldades na disciplina de matemática até ao ponto de considerar os momentos de avaliação como períodos de grande ansiedade. As diferenças nas conceções sobre a avaliação também são visíveis em outros aspetos, nomeadamente, os relacionados com os intervenientes deste processos, a função de cada um deles e a importância e interesse que têm os resultado das avaliações. Nestes casos, Paulo, ao contrário de João, demonstrou uma conceção de avaliação mais orientadora e reguladora.

Que práticas de avaliação os professores seguem na sua sala de aulas? Que estratégias, técnicas e instrumentos de avaliação usam?

A importância que a avaliação sumativa assume no processo avaliativo está evidenciada nas práticas avaliativas que João diz implementar, em que o teste escrito é o instrumento mais utilizados na avaliação das aprendizagens dos seus alunos. João também apontou outros instrumentos de avaliação, como "exercícios" realizados individualmente ou em grupos, ficha de autoavaliação ou grelhas de observação. Esta grelha inclui o comportamento, a assiduidade, a pontualidade e a "participação útil", pois, como sublinha, "não basta abrir a boca, mas sim falar com verdade". Esta referência à "participação útil" pode ser entendida com uma conotação essencialmente classificatória, facto que contradiz o seu conceito de avaliação, dado que os critérios usados na observação não são concretizados com uma intenção orientadora.

Atendendo aos instrumentos de avaliação que Paulo afirma utilizar com mais frequência, "exercícios, provas escritas e trabalhos de pesquisas", aos momentos e à frequência das avaliações produzidas, as suas práticas avaliativas também evidenciam uma avaliação preferentemente centrada nos produtos. No entanto, denota-se, no seu discurso, uma grande preocupação com a avaliação para a aprendizagem, "avaliar não é só dar uma classificação: implica refletir com o aluno o que falhou, por que falhou e ver o que é necessário mudar", embora não tenha ficado explícita a forma como ela é desenvolvida na prática.

Os participantes parecem não reconhecer uma grande utilidade da avaliação diagnóstica no processo de ensino e aprendizagem. Paulo utiliza esta modalidade de avaliação somente quando está perante novos alunos. João diz utilizá-la essencialmente no início da abordagem de cada novo conteúdo ou quando deteta alguma lacuna na aprendizagem dos alunos.

Já a avaliação formativa, para os dois participantes, emerge com uma função orientadora e reguladora do processo de ensino e aprendizagem seguindo, entre outros, Hoffmann (2008) e Perrenoud (1999). Todavia, não ficou claro nesta investigação como é feita a articulação entre a avaliação formativa e a avaliação sumativa. No momento de classificar os seus alunos, os dois professores consideram o resultado dos alunos nos testes como uma parte significativa da avaliação. João atribui-lhe uma percentagem de $75 \%$, enquanto Paulo atribui o peso de $50 \%$ a cada uma das avaliações e usa a "nota" da observação para equilibrar as médias em caso de necessidade, o que deixa transparecer alguma subjetividade deste processo.

As informações recolhidas com o "instrumento de observação" parecem ser pouco valorizadas e não é clara a importância e a função que os desempenhos observados assumem no processo de aprendizagem. As dificuldades no "processamento" das informações registadas pelos professores podem estar associadas quer à natureza das grelhas de avaliação utilizadas quer às próprias competências que os professores pretendem avaliar, parecendo ajudar pouco nas "decisões" a tomar. Foi notório que o processo de recolha de informações implementado pelos participantes não teve um caráter sistemático, organizado, pré-definido ou com objetivos precisos, condições importantes para o desenvolvimento de uma avaliação para aprendizagem (Hoffmann, 2008).

Que fatores condicionam as práticas avaliativas dos professores? Que fatores incidem positiva ou negativamente na ação ao elaborar, organizar e desenvolver a sua atividade avaliativa?

Os dois professores consideram que as suas práticas avaliativas sofrem múltiplas influências do sistema de ensino oficial, do currículo, do percurso profissional, da experiência enquanto estudante, das condições de exercício da função docente, da comunidade profissional ou dos alunos.

Os alunos são referidos como um dos fatores mais importantes. A falta de "pré-requisitos", pouca 
motivação pelos estudos, absentismo e a não pontualidade aparecem como os principais aspetos negativos apontados nesta categoria. Mas, como recorda Luckesi (1999), cabe ao professor desafiar os alunos a superar as dificuldades a fim de progredirem e melhorarem o seu conhecimento.

Outro fator que influencia a escolha das estratégias de avaliação e condiciona as práticas de João e Paulo é o próprio professor, em especial, a sua experiência enquanto estudante e os hábitos acumulados ao longo de tempo. Como destacam Fernandes (2005, 2006), Hoffmann (2008) ou Perrenoud (1999), o fator "experiência" parece conferir aos professores um sentimento de segurança nas suas atuações. O percurso profissional e a experiência como estudantes também desempenham um papel significativo nas estratégias de avaliação que os professores dizem privilegiar, pelo que importa focalizar a importância na formação e na capacitação dos docentes de modo a implicá-los com o novo paradigma de avaliação (Fernandes, 2006).

O contexto de trabalho é outro aspeto realçado pelos dois professores que, no caso, consideram pouco favorável ao desenvolvimento de práticas avaliativas diversificadas. A falta de uma biblioteca bem apetrechada, a dificuldade de acesso às novas tecnologias de comunicação e informação, as normas do sistema avaliativo ou a pouca importância dada à problemática do absentismo e da não pontualidade dos alunos constituem obstáculos reais à atuação dos professores, contribuindo para a sua desmotivação, o que afeta em grande medida as suas práticas docentes.

\section{Conclusão}

De acordo com a análise de dados fica explícito que os professores participantes retratam nos seus discursos conceções sobre avaliação bastante próximas, com conceitos associados tanto à avaliação da aprendizagem como à avaliação para a aprendizagem. Globalmente, mostram uma disposição para pressupostos da avaliação orientadora e reguladora do processo de ensino e aprendizagem, levando a crer que se encontram numa fase transitória, estando a passar por um momento de transformação relativamente às metodologias envolvidas no processo de avaliação das aprendizagens dos seus alunos. Na análise dos seus discursos sobre conceitos, finalidades e principais papéis desempenhados no processo de ensino e aprendizagem, a avaliação é vista como reguladora deste processo. Mas, atendendo aos instrumentos de avaliação mais utilizados (teste escrito), aos momentos em que são realizados e ao tratamento dos resultados obtidos pelos alunos, as práticas dos participantes estão mais próximas de uma avaliação da aprendizagem, reforçando a sua função classificativa. Como principais fatores condicionantes das respetivas práticas avaliativas, os professores participantes destacam os alunos, as condições de trabalho e o próprio professor.

Para concluir, reconhece-se os limites da análise muito centrada nos discursos dos professores participantes. A escuta dos alunos e dos demais envolvidos no processo de avaliação, a observação do quotidiano dos professores e dos alunos nas suas interações durante as aulas, certamente, propiciariam uma compreensão mais global e mais aprofundada sobre todo o processo avaliativo. Mas acreditamos que este estudo, sendo pioneiro em São Tomé e Príncipe, abre caminhos para outras investigações tendo em conta a importância, a extensão a complexidade do tema abordado.

\section{Referências}

Arantes, M.J. (2004). Conceções e práticas de avaliação de professores estagiários de matemática. Dissertação de mestrado, Universidade do Minho, Braga, Portugal. https://repositorium.sdum.uminho.pt/bitstrea m/1822/716/1/Tese\%20Mestrado.pdf

Abrantes, P. (1995). Avaliação e educação matemática. Reflexões em Educação Matemática, Vol. 1, Grupo de Estudos e Pesquisa em Educação Matemática, Brasil. http://www.gepem.ufrrj.br

Bogdan, R., \& Biklen S. (1994). Investigação qualitativa em educação. Uma introdução à teoria e aos métodos. Porto: Porto Editora.

Chaves, S.M. (2003). Avaliação da aprendizagem no ensino superior. Realidade, complexidade $e$ possibilidades. Tese de doutoramento, Universidade Federal de Gaia, São Paulo, Brasil.

Fernandes, D. (2004). Avaliação das aprendizagens: Uma agenda, muitos desafios. Lisboa: Porto Editora.

Fernandes, D. (2005). Avaliação das aprendizagens: Desafios às teorias, práticas e políticas. Lisboa: Porto Editora.

Fernandes, D. (2006). Para uma teoria da avaliação formativa. Revista Portuguesa de Educação, 19(2), 21-50.

Hadji, C. (2001). Avaliação desmistificada. Porto Alegre: Artmed.

Haydt, R. (1997). Avaliação do processo de ensino e aprendizagem. São Paulo: Ática.

Hoffmann, J. (2008). Avaliação mediadora: Uma prática em construção da pré-escola à universidade. Porto Alegre: Mediação.

Instituto Superior Politécnico de São Tomé e Príncipe (ISP-STP). (2009). Sistema de avaliação. São Tomé: ISP, São Tomé e Príncipe.

Lessard-Hébert M., Goyette, G. \& Boutin, G. (2005). Investigação qualitativa: Fundamentos e práticas. Lisboa: Instituto Piaget.

Luckesi, C. (1999). Avaliação da aprendizagem escolar. São Paulo: Cortez.

National Council of Teachers of Mathematics. (2007). Princípios e normas para a matemática escolar. Lisboa: Associação de Professores de Matemática.

Perrenoud, P. (1999). Avaliação: Da excelência à regulação das aprendizagens - entre duas lógicas. Porto Alegre: Artmed.

Sant'Anna, I.M. (1995). Por quê avaliar? Como avaliar? Critérios e instrumentos. Petrópolis: Vozes. 